\title{
Bioluminescent Monitoring: Detoxification of Phenol Solutions by Humic Substances and UV-irradiation
}

\author{
Anna S. Tarasova ${ }^{a *}$, Nadezhda S. Kudryasheva ${ }^{a, b}$, \\ Elena S. Fedorova ${ }^{a, b}$, Devard I. Stom ${ }^{c}$ \\ a Siberian Federal University, \\ 79 Svobodny, Krasnoyarsk, 660041 Russia \\ ${ }^{b}$ Institute of Biophysics of Siberian Branch of Russian Academy of Sciences, \\ Akademgorodok, Krasnoyarsk, 660036 Russia \\ ' Irkutsk State University, Biology Research Institute, \\ 5 Suche-Bator Street, Irkutsk, 664003 Russia ${ }^{I}$
}

Received 2.06.2008, received in revised form 25.08.2008, accepted 27.08.2008

The study demonstrates redox activity of humic substances in solutions of organic reducers and oxidizers; a series of homologous 1,4-hydroquinones (phenols) and their oxidized forms (1,4-quinones) was taken as an example. The well-founded interrelation between redox potentials of the quinonephenols pairs and detoxification coefficients in the humic solutions was ascertained. Photoinduced $U V$ detoxification of the phenol solutions was revealed; combined effect of humic substances and UV irradiation in the phenol solutions was studied as well. Detoxification coefficients were calculated. A conclusion was made that $U V$-irradiation and treatment by humic substances reveal non-additive but antagonistic effect.

Keywords: bioluminescent assay, detoxification, humic substances, UV-irradiation, phenols and quinones.

\section{Introduction}

One of the important tasks of modern ecology and biotechnology is the search of methods to detoxify the environmental toxicants. A possible way to do this is to use Humic Substances (HS) the products of oxidative transformation of organic matter in soil (Orlov, 1998, 2002; Shin et al., 1999). Toxicity of some compounds was shown to decrease in the presence of HS (Perminova et al., 2001; Gu et al., 2003; Zhilin et al., 2004). The mechanism of detoxification by HS is currently of great interest for researchers (Stom et al., 1977,
2004; Grainer et al., 1999; Vigneault et al., 2000; Perminova et al., 2001; Kulikova et al., 2002; Provenzano et al., 2004).

In (Donnelly et al., 1997; Weinstein et al., 1999), the detoxification effects of HS were studied using classic bioassays involving fish, algae, crustaceans, or plants. Detoxifying effect of HS can be easily evaluated by bacterial bioluminescent assay (Kudryasheva et al., 1998). The advantages here are rapidity, sensitivity, simplicity of analysis, and availability of the

\footnotetext{
Corresponding author E-mail address: AS421@yandex.ru (C) Siberian Federal University. All rights reserved
} 
devices for toxicity registration (Kratasyuk et al., 1987).

Bioluminescent bacteria have been used as a bioassay for almost a half of a century. The bioassay was described in its current form in 1969 (Grabert et al., 1997). In the late 1980s the test was standardized in Germany as a method forpollutants' detection. In 1990 the bioluminescent system of enzymatic coupled reactions was suggested as a toxicity assay (Kratasyuk et al., 1990); its applications were developed (Kudryasheva et al., 2002, 2003). Now, the ecological bioassay is a traditional and important biotechnological application of the bioluminescence phenomenon (Girotti et al., 2008; Gitelson, et al., 2002; Roda et al., 2004; Kudryasheva 2006, 2006b, Lapota et al., 2008; Cali et al., 2008; Vlasova et al., 2007; Reis et al., 2007; Vetrova et al., 2007).

Testing of redox activity of HS in solutions of oxidizers and reducers is of great interest. Reduction ability of HS was supposed to be responsible for detoxification of oxidizers in water solutions (Tchaikovskaya et al., 2006; Fedorova et al., 2007). Phenolic, SH-, and other groups of HS macromolecules are responsible for reduction of the oxidizers.

Testing of oxidative activity of HS in solutions of organic reducers (phenols) is of applied interest. In the present study we chose a series of homologous phenols: tetrafluoro1,4-hydroquinone, 1,4-hydroquinone, and 1,4naphthohydroquinone. We compared them with a series of corresponding homologous oxidizers: tetrafluoro-1,4-benzoquinone, 1,4-benzoquinone, 1,4-naphtoquinone, (Fedorova et al., 2007).

In natural conditions, detoxification of solutions by HS might take place under UV and visible light. This is why the study of photoinduced detoxification of pollutants in the presence and absence of HS is of urgent need. In (Tchaikovskaya et al., 2006, 2007), the toxicity of phenol and p-cresol solutions has already been monitored under combined effect of HS and UVirradiation.

The aim of the present study was to reveal detoxification of the homologous phenol $(1,4-$ hydroquinones) solutions by HS, UV-irradiation, and combination of $\mathrm{HS}+\mathrm{UV}$-irradiation. Bioluminescent system of the coupled enzyme reactions was used as a bioassay.

\section{Materials and Methods}

A series of hydroquinone preparations was used: tetrafluoro-1,4-hydroquinone (Aldrich, 95\% purity), 1,4-hydroquinone, and 1,4naphthohydroquinone (ChimReactiv, Russia, analytical grade).

Humic preparation Humate-80 (OOO "Humate", Irkutsk, Russia) was applied as a source of HS. It was produced by non-extracting treatment of coal with alkali treatment. The preparation includes more than $70 \%$ of potassium humate, providing high biological and chemical activity (Levinsky, 2000). Concentrations of HS that inhibit bioluminescence by less than $20 \%$ (< $0.3 \mathrm{~g} / \mathrm{L}$ ) were used.

Quartz lamp OUFQ-1 (OOO 'Solnishko', Russia) was applied as a source of UV-irradiation. $1 \mathrm{ml}$ of a phenol solution was irradiated during 30 $\min$ in $1 \times 1 \mathrm{~cm}^{2}$ quartz cell.

Absorption spectra were recorded with a double-beam spectrophotometer UVIKON-943 (KONTRON Instruments, Italy).

Toxicity of the hydroquinone water solutions was assessed by bioluminescent assay based on a NADH:FMN-oxidoreductase-luciferase $(\mathrm{R}+\mathrm{L})$ coupled enzyme system from Photobacterium phosphoreum. To construct the assay system, 0.1 $\mathrm{mg} / \mathrm{ml} \mathrm{L}+\mathrm{R}, 5 \cdot 10^{-4} \mathrm{M}$ FMN, $10^{-4} \mathrm{M} \mathrm{NADH}$, and $0.002 \%$ tetradecanal solutions were used. The assay was performed in $0.1 \mathrm{M}$ phosphate buffer (pH 6.8) at room temperature.

Maximal luminescent intensity was determined in control (without hydroquinones 
- $\left.I_{\text {contr }}\right)$ and experimental (I) samples. Relative intensity $I^{r e l}=I / I_{\text {contr }}$ was used to evaluate the effect of the hydroquinones on bioluminescence. Dependence of $I^{\text {rel }}$ onhydroquinone concentration was developed. Hydroquinones' concentration inhibiting bioluminescence to $40 \%$ of the control intensity $\left(C_{40}\right)$ was chosen. It was used in the experiments for studying the detoxification processes in hydroquinone solutions.

Symbols of bioluminescence intensity $\left(I^{r e l}\right)$ in solutions of the hydroquinones under treatment by HS, UV-irradiation, and HS+UV were: $I_{H S}^{r e l}, I_{U V}^{r e l}$, and $I_{H S+U V}^{r e l}, \quad$ respectively. Detoxification coefficients $K_{H S}, K_{U V}$ and $K_{H S+U V}$ were calculated as the intensity ratio in the presence and the absence of detoxification factor, with the latter equaling $0.4\left(I^{\text {rel }}=0.4\right)$ :

$$
\begin{gathered}
K_{H S}=I_{H S}^{r e l} / I^{r e l}=I_{H S}^{r e l} / 0.4 \\
K_{U V}=I_{U V}^{r e l} / I^{r e l}=I_{U V}^{r e l} / 0.4 \\
K_{H S+U V}=I_{H S+U V}^{r e l} / I^{r e l}=I_{H S+U V}^{r e l} / 0.4
\end{gathered}
$$

\section{Results and discussion}

Dependence of $I^{\text {rel }}$ on hydroquinone concentration was investigated in the solutions of tetrafluoro-1,4-hydroquinone, 1,4-hydroquinone, and 1,4-naphthohydroquinone. Fig. 1 presents the experimental dependence with 1,4naphthohydroquinone taken as an example. The figure shows the decay of the experimental curve. The phenol concentration that inhibited bioluminescence to $40 \%$ of the control intensity $\left(C_{40}=2.5 \cdot 10^{-5} M\right)$ is shown in this figure, as well.

\section{Detoxification by $\mathrm{HS}$}

Detoxification ability of HS was compared in solutions of 1,4-hydroquinones and corresponding 1,4-quinones. Fig. 2 presents these redox quinonehydroquinone pairs. Their standard redox potentials are given in Table $1 \mathrm{a}$.

Table $1 \mathrm{a}, \mathrm{b}$ demonstrates $K_{H S}$ in the solutions of 1,4-hydroquinones and corresponding 1,4quinones. It is evident that $K_{H S}$-values are in a direct dependence on $E^{0}$-values in the series of both, hydroquinones and quinones. This reveals HS' reductive (antioxidant) activity in the solutions of the organic oxidizers, as well as HS' oxidative activity in the solutions of organic reducers.

\section{UV-photoinduced detoxification}

Effect of UV-irradiation of phenol solutions was studied. Table $1 \mathrm{~b}$ presents $K_{U V}$ values in the hydroquinone solutions. They appeared to be $>1$, indicating photoinduced detoxification of the solutions. In addition, the values of $K_{U V}$ were similar for the solutions of all three phenols (Table 1b).

Fig. 3a-c presents the absorption spectra of 1,4-hydroquinones before and after UVirradiation. It is seen that the optical density (O.D.) of tetrafluoro-1,4-hydroquinone solution increases under UV-irradiation in the region of the spectral maximum (260-290 nm) (Fig. 3a). Detoxification of the compound was probably due to its dehalogenation; this process can be highly effective in haloid organic compounds under UVirradiation (Shigorin et al., 1993). UV maximum of 1,4-hydroquinone (Fig. 3b) does not change significantly under UV-treatment. However, wide and structureless band appears in a visible wavelength range of 350-600 $\mathrm{nm}$. Usually, this band is attributed to the charge-transfer complexes in solutions of 1,4-benzoquinone and 1,4-hydroquinone. Fig. 3c shows the changes in spectra of 1,4-hydronaphthoquinone. The optical density of spectrum 2 does not reach zero in the visible spectral range, thus revealing the contribution of light scattering to this spectrum. It seems to be a result of the formation of hydrophobic aggregates in the process of photolysis of 1,4-hydronaphthoquinone. Thus the changes in the absorption spectra of solutions of 1,4hydroquinones are an evidence of photochemical transformation of these phenols in the solutions. 


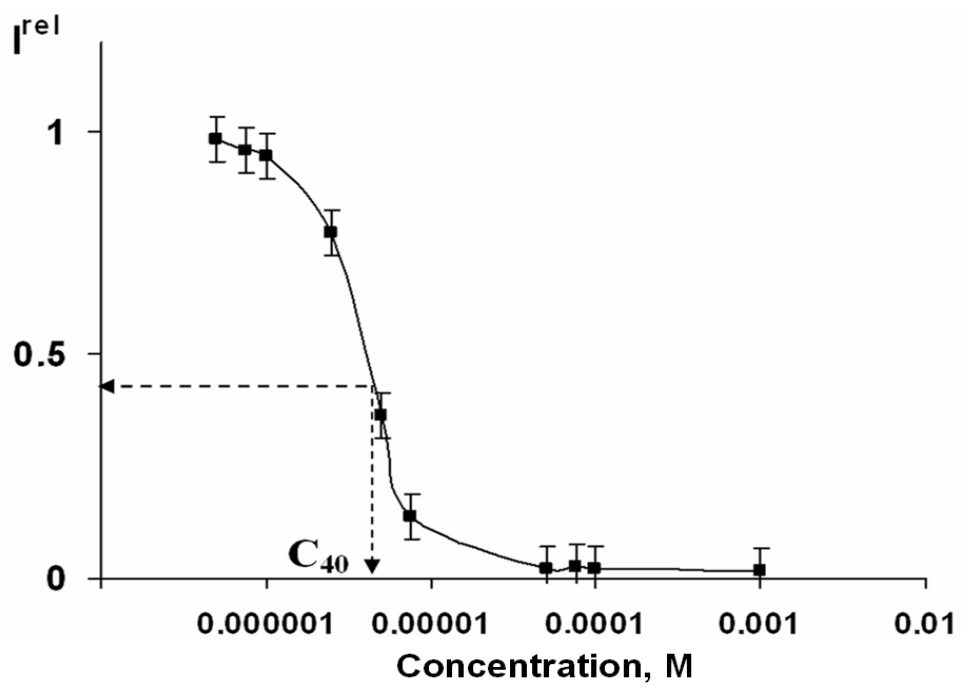

Fig. 1. Bioluminescence intensity vs. concentration of 1,4-naphthohydroquinone

Table 1. Detoxification of solutions: (a) 1,4-quinones (Fedorova et al., 2007) (b) 1,4-dihydroquinones. $K_{H S}$ - detoxification coefficient under HS treatment, $K_{U V}$ - detoxification coefficient under UV-irradiation, $K_{H S+U V}$ - detoxification coefficient under combined effect of HS and UV-irradiation, $E^{0}$ - standard redox potential of quinone-hydroquinone pairs, $C_{40}$ - phenol concentration inhibiting bioluminescence to $40 \%$ of control intensity

(a)

\begin{tabular}{c|c|c|c}
\hline quinones & $\begin{array}{c}\text { tetrafluoro-1,4- } \\
\text { benzoquinone }\end{array}$ & 1,4-benzoquinone & 1,4-naphtoquinone \\
\hline$C_{40}, M$ & $2 \cdot 10^{-4}$ & $1 \cdot 10^{-4}$ & $4 \cdot 10^{-4}$ \\
$K_{H S}$ & $2.11 \pm 0.03$ & $1.73 \pm 0.02$ & $0.92 \pm 0.02$ \\
$E^{0}, V$ & 0.838 & 0.712 & 0.480 \\
\hline
\end{tabular}

(b)

\begin{tabular}{c|c|c|c}
\hline phenols & $\begin{array}{c}\text { tetrafluoro-1,4- } \\
\text { hydroquinone }\end{array}$ & 1,4-hydroquinone & $\begin{array}{c}\text { 1,4-naphtho- } \\
\text { hydroquinone }\end{array}$ \\
\hline$C_{40}, M$ & $6 \cdot 10^{-7}$ & $2.5 \cdot 10^{-2}$ & $2.5 \cdot 10^{-5}$ \\
$K_{H S}$ & $1.00 \pm 0.04$ & $1.18 \pm 0.03$ & $2.10 \pm 0.02$ \\
$K_{U V}$ & $1.4 \pm 0.04$ & $1.25 \pm 0.02$ & $1.30 \pm 0.02$ \\
$K_{H S+U V}$ & $1.7 \pm 0.04$ & $1.01 \pm 0.02$ & $1.46 \pm 0.03$ \\
\hline
\end{tabular}


a)<smiles>O=C1C(=[18O])C(F)=C(F)C(F)=C1F</smiles>

b)<smiles>O=C1C=CC(=O)C=C1</smiles>

c)<smiles>O=C1C=CC(=O)c2ccccc21</smiles>

Fig. 2. Redox pairs quinone-phenol: (a) tetrafluoro-1,4-benzoquinone - tetrafluoro-1,4-hydroquinone, (b) 1,4-benzoquinone-1,4-hydroquinone, (c) 1,4-naphthoquinone - 1,4-naphthohydroquinone 

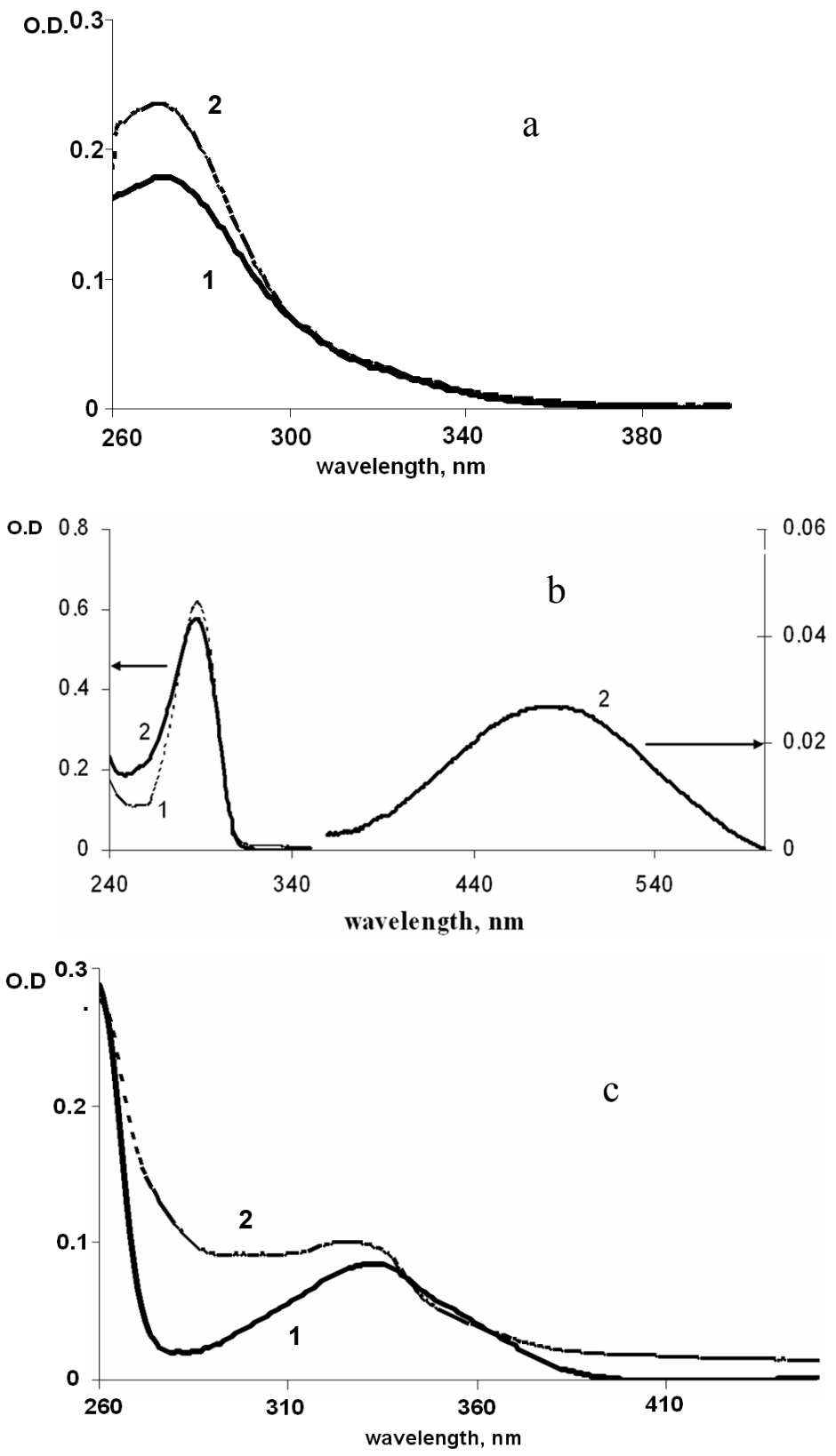

Fig. 3. Absorbance spectra of phenol solutions: (1) before UV-irradiation, (2) after UV-irradiation: (a) tetrafluoro-1,4-hydroquinone $\left(\mathrm{C}=6 \cdot 10^{-7} \mathrm{M}\right)$; (b) 1 ,4-hydroquinone $\left(\mathrm{C}=1.25 \cdot 10^{-3} \mathrm{M}\right)$;

(c) 1,4-naphthohydroquinon $\left(\mathrm{C}=2.5 \cdot 10^{-5} \mathrm{M}\right)$ 
3. Combined effect of $\boldsymbol{H S}$ and $\boldsymbol{U V}$ - of HS was demonstrated in the solutions of irradiation

Table $1 \mathrm{~b}$ presents $K_{H S+U V}$ of $1,4-$ organic reducers - 1,4-hydroquinones (phenols). hydroquinones. Comparison of $K_{H S+U V}, K_{H S}$, and $K_{U V}$ values brings to conclusion that the combined effect of the two detoxifying factors (HS+UV) is not additive. The complex photoinduced processes taking place in quinone solutions in the presence of HS might account for this fact. Non-additivity of HS and UV effects was already found in the solutions of phenol and p-cresol (Tchaikovskaya et al., 2006, 2007).

\section{Conclusion}

The effects of two detoxifying factors (HS and UV-irradiation) as well as the combined effects (HS+UV) on solutions of 1,4-hydroquinones were studied. Detoxification coefficients were calculated.

The reduction activity of HS was demonstrated in the solutions of organic oxidizers - 1,4-quinones, while the oxidative activity

The interrelations between redox-potentials of quinone-hydroquinone pairs and detoxification coefficients in solutions of 1,4-quinones and 1,4hydroquinones were revealed.

Photoinduced detoxification of 1,4hydroquinones solutions was demonstrated. UV-irradiation and treatment by HS revealed non-additive but antagonistic effect in the phenol solutions.

\section{Acknowledgements}

The work was supported by: Award No. RUX0-002-KR-06 of the U.S. Civilian Research \& Development Foundation (CRDF) and RF Ministry of Education and Science, BRHE Program; Grant "Molecular and Cellular Biology", program of Russian Academy of Sciences; Innovation program for young scientists of Siberian Federal University.

\section{References}

Cali J.J., Niles A., Valley M.P., O’Brien M.A., Riss T.L., Shultz J. (2008) Bioluminescent assays for ADMET. Expert Opinion On Drug Metabolism \& Toxicology, 4: 103-120

Donnelly K., Chen J., Huebner H., Brown K. (1997) Utility of four strains of white-rot fungi for the detoxification of 2,4,6-trinitrotoluene in liquid culture. Environ. Toxic. Chem., 16: 1105-1110

Fedorova E., Kudryasheva N., Kuznetsov A., Mogil'naya O., Stom D. (2007) Bioluminescent Monitoring of Detoxification Processes: Activity of Humic Substances in Quinone Solutions. J. Photochem. Photobiol B, 88: 131-136

Gitelson J.I., Kratasyuk V.A., et al., (2002) Ecological Biophysics., V. 1. Photobiophysics of ecosystems, Logos, Moscow, 114-121

Girotti S., Ferri E.N., Fumo M.G., Maiolini E. (2008) Monitoring of environmental pollutants by bioluminescent bacteria. Anal. Chim. Acta, 608: 2-29

Grabert E., Kossler F. (1997) About the effect of nutrients on the luminescent bacteria test. In: Hastings J.W., Kricka L.J., Stanley P.E. (ed.) Bioluminescence and Chemiluminescence, Wiley, Chichester, p. 291-294

Grainer L., Lafrance P., Campbell P. (1999) An experimental design to probe the interactions of dissolved organic matter and xenobiotics: Bioavailability of pyrene and 2,2',5,5'-tetrachlorobiphenyl to Daphnia magna. Chemosphere, 38: 335-350 
Gu B., Chen J. (2003) Enhanced microbial reduction of Cr (VI) and U (VI) by different natural organic matter fractions. Geochim. Cosmochim. Acta 67: 3575-3582

Kratasyuk V.A., Gitelson J.I. (1987) The application of luminous bacteria in bioluminescent assays. Uspekhi mikrobiologii, 21: 3-30

Kratasyuk V.A. (1990) Principles of luciferase biotesting. In: Jezowska-Trzebiatowska B., Kochel B., Stawinski J., Strek I. (ed.) Biological Luminescence, World Scientific, Singapore, p. 550-558

Kudryasheva N., Esimbekova E., Vetrova E., Kudinova I.(1998) Development of the bioluminescent bioindicators for analyses of pollutions. Field Analytical Chemical Technologies, 2: 277-280

Kudryasheva N., Vetrova E., Kuznetsov A., Kratasyuk V., Stom D. (2002) Bioluminescent assays: effects of quinones and phenols. Ecotoxicology and Environmental Safety, 53: 221-225

Kudryasheva N.S., Esimbekova E.N., Remmel N.N., Kratasyuk V.A., Visser A.J.W.G., van Hoek A. (2003) Effect of quinones and phenols on the triple enzymic bioluminescent system with protease. Luminescence, 18: 224-228

Kudryasheva N.S. (2006) Bioluminescence and exogenous compounds. Physico-chemical basis for bioluminescent assay. J. Photochem. Photobiol. B, 1: 77-86

Kudryasheva N. (2006) Nonspecific effects of exogenous compounds on bacterial bioluminescent enzymes: Fluorescence study. Current Enzyme Inhibition, 4: 363-372

Kulikova N., Perminova I. (2002) Binding of atrazine to humic substances from soil, peat, and coal related to their structure. Environ. Sci. Technol. 36: 3720-3724

Lapota D., Osorio A.R., Liao C., Bjorndal B. (2008) The use of bioluminescent dinoflagellates as an environmental risk assessment tool. Marine Pollution Bulletin, 54: 1857-1867

Levinsky B. (2000) All about humates. Korf-Poligraf, Irkutsk, p. 25-50

Orlov D. (1998) Organic matter of Russian soil. Pochvovedeniye 9: 1049-1057

Orlov D. (2002) Humic substances in hydrosphere. Soros Educ. J. 2: 56-63

Perminova I., Grechishcheva N., Kovalevskii D., Kudryavtsev A., Petrosyan V., Matorin D. (2001) Quantification and prediction of the detoxifying properties of humic substances related to their chemical binding to polycyclic aromatic hydrocarbons. Environ. Sci. Technol. 35: 3841-3848

Provenzano M., D’Orazio V., Jerzykiewiez M., Senesi N. (2004) Fluorescence behaviour of Zn and Ni complexes of humic acids from different source. Chemosphere 55: 885-892

Reis J.L.R., Dezotti M., Sant'Anna G.L. (2007) Toxicity evaluation of the process effluent streams of a petrochemical industry. Env. Tech, 28: 147-155

Roda A., Pasini P., Mirasoni M., Michchelini E., Guardigli M. (2004) Biotechnological application of bioluminescence and chemiluminescence. Trends in Biotechnology 22: 295-303

Shigorin D.N., Val'kova G.A., Gastilovich E.A. (1993) Electron-excited states of polyatomic molecules. Moscow, Nauka, 495 p.

Shin H., Monsallier J., Choppin G. (1999) Spectroscopic and chemical characterization of molecular size fractionated humic acid. Talanta 50: 641-647

Stom D. (1977) Influence of polyphenols and quinones on aquatic plants and their blocking of SHgroups. Acta Hydrochim. Hydrobiol., 5: 291-298

Stom D., Dagurov A. (2004) Cooperation action petroleum products and humic substances on Daphnia magna. Sib. Ecol. Zh. 1: 35-40 
Tchaikovskaya O., Sokolova I., Svetlichniy V., Karetnikova E., Fedorova E., Kudryasheva N. (2007) Fluorescent and bioluminescent analysis of sequential biological UV degradation of p-cresol in water. Luminescence, 22: 29-34

Tchaikovskaya O.N., Sokolova I.V., Svetlichniy V.A., Karetnikova E., Kudryasheva N.S., Fedorova E.N. (2006) Luminescent analysis of photoinduced detoxification of phenol. Zhurnal Prikladnoy Spektroskopii, 73: 665-670

Vetrova E., Esimbekova E., Remmel N., Kotova S., Beloskov N., Kratasyuk V., Gitelson I. (2007) A bioluminescent signal system: detection of chemical toxicants in water. Luminescence, 22: 206-214

Vigneault B., Percot A., Lafleur M., Campbell P. (2000) Permeability changes in model and phytoplankton membranes in the presence of aquatic humic substances. Environ. Sci. Technol. 34: 3907-3913

Vlasova I.I., Asrieli T.V., Gavrilova E.M., Danilov V.S. (2007) Determination of antibiotics using luminescent Escherichia coli and blood serum. Appl. Biochem. Microbiol., 43: 422-428

Weinstein J., Oris J. (1999) Humic acids reduce the bioaccumulation and photoinduced toxicity of fluoranthene to fish. Environ. Toxic. Chem. 18: 2087-2094

Zhilin D., Schmitt-Kopplin P., Perminova I. (2004) Reduction of Cr(VI) by peat and coal humic substances. Environ. Chem. Lett. 2: 141-145. 